Brito, L.M.T. "De "papai sabe tudo" a "como educar seus pais". Considerações sobre programas infantis de TV"

\title{
DE "PAPAI SABE TUDO" A "COMO EDUCAR SEUS PAIS". CONSIDERAÇÕES SOBRE PROGRAMAS INFANTIS DE TV
}

\author{
Leila Maria Torraca de Brito \\ Universidade do Estado do Rio de Janeiro
}

RESUMO: Este artigo procura evidenciar o conteúdo implícito de certos programas infanto-juvenis apresentados na TV nos últimos quarenta e cinco anos, relacionando-os às transformações observadas na família contemporânea e ao processo de socialização de crianças e adolescentes. Foi avaliado que a autoridade dos responsáveis tem sido, progressivamente, desvalorizada em diversos programas televisivos, oferecendo-se superpoderes, até mesmo tirânicos às crianças, em desacordo com as necessidades infanto-juvenis.

PALAVRAS-CHAVE: Família e Mídia; Programas infantis na TV; Socialização infanto-juvenil

\section{FROM "FATHER KNOWS BEST" TO "HOW TO EDUCATE YOUR PARENTS" CONSIDERATIONS REGARDING CHILDREN'S TELEVISION PROGRAMS}

ABSCTRACT: This article intends to evidence the implicit content of certain children and teenager's television programs in the last forty five years, linking them to the changes observed in the contemporary family and the children's socialization processes. It was assessed that the parental authority has been gradually depreciated in several television programs. These programs offer super and even tyrannical power to the children, which is not in appropriate to the needs of the underaged.

KEY WORDS:: family and media, children's television programs, children and teenagers' socialization.

\section{INTRODUÇÃO}

As alterações presenciadas na família ocidental contemporânea são constantemente evocadas a partir da referência às novas organizações familiares, ou aos papéis desempenhados por seus membros. No entanto, uma análise de tais mudanças não pode deixar de relacionar aspectos sociais, políticos, tecnológicos, econômicos e ideológicos presentes em cada cultura; fatores interligados ao processo, dinâmico, de construção de subjetividades.

Ao empreender pesquisa sobre o exercício dos papéis parentais após a separação conjugal (BRITO, 2002), foi observado que tanto em referências bibliográficas utilizadas (ROCHA-COUTINHO, 2001; NOLASCO, 2001) quanto nas entrevistas feitas no decorrer da investigação, expressões ou títulos de programas infanto-juvenis apresentados na TV eram citados e relacionados ao comportamento de pais e mães. Esse dado instigou a curiosidade sobre o conteúdo da programação, que parecia assimilado na referência e na comparação de condutas e ações, suscitando o interesse pelo tema.

Por este motivo, propõe-se aqui uma reflexão sobre o percurso da programação infanto-juvenil veiculada na televisão nos últimos quarenta e cinco anos, optando-se por uma análise conjunta dos programas de acordo com a época de seu lançamento no Brasil, notadamente no Rio de Janeiro e em São Paulo. São apontados possíveis padrões comuns desta programação destinada ao público infantil, procurando-se avaliar como retratam as mudanças observadas na família ocidental contemporânea.

Parte-se do princípio de que o contexto social reafirma valores e modelos de conduta difundidos de forma implícita pelos meios de comunicação, que, em um movimento dialético, mesclam átomos da projeção com os da assimilação, assim como os da informação aos da formação - oferta que contribui para uma apropriação mais rápida do novo, quando naturalizado. Neste movimento, o sujeito - leitor, ouvinte e telespectador -, se situa como autor, agente da ação, quando se identifica com os comportamentos apresentados, e como espectador, ao assistir novos padrões ofertados coletivamente. Assim, a comunicação atinge a subjetividade de "consumidores em potencial", afetando formas de viver, de construir e de se constituir nesta realidade sócio-histórica.

No caso da televisão, não se pode desprezar o dado de que os mesmos desenhos e seriados infantis são diariamente oferecidos pela grade de programação, apresentando temas e personagens recorrentes, além de possuírem difusão globalizada. Como aponta Sarlo (1995):

"como o folhetim, a televisão repete uma es- 
trutura, um esquema de personagens, um conjunto pequeno de tipos psicológicos e morais, um sistema de peripécias e, inclusive, uma ordem de peripécias." (p.67-68).

Os programas e desenhos destacados neste artigo referem-se àqueles relacionados por cinqüenta e cinco telespectadores de distintas faixas etárias ${ }^{1}$ (vinte e dois do sexo masculino e vinte e três do sexo feminino), que foram consultados a respeito da programação a que assistiam em sua infância. Observou-se, todavia, que as pessoas geralmente não se limitavam a indicar um único programa, mas relacionavam diversos, a partir da argumentação de que eram veiculados sucessivamente e de que, comumente, quando assistiam à televisão, não se restringiam a acompanhar um único desenho. Assim, recordavam uma série de discursos, ações e comportamentos de muita semelhança que eram apresentados, remetendo à idéia de matriz comum, classificada por alguns autores como o "habitus" na comunicação (BARROS FILHO E MARTINO, 2003). Por esse motivo, foi considerado, no trabalho, que uma avaliação isolada de cada desenho restringiria o campo de reflexão, optando-se por uma análise do que era veiculado em cada década.

Os desenhos e programas mais destacados pelos sujeitos da amostra foram assistidos, diversas vezes, e agrupados de acordo com a época de seu lançamento no Brasil. Na análise das produções indicadas foram consideradas as representações parentais e os papéis atribuídos às figuras masculinas e às femininas, relacionando-se esses dados às transformações presenciadas na família contemporânea. À semelhança de Medrado (1998) - que analisou o repertório de peças publicitárias na representação do gênero masculino - as imagens e discursos veiculados nos programas selecionados no presente trabalho foram entendidas como produções discursivas que, como define o autor, “....ampliam o leque de repertórios disponíveis aos sujeitos, possibilitando a produção de novos sentidos e a construção de versões diversas sobre si próprio e sobre o mundo a sua volta." (p.148).

Em conversas sobre o tema, alguns telespectadores consultados lembravam, ainda, programas e seriados atuais - próprios para adultos que reproduziam o mesmo padrão observado nos desenhos estudados, motivo pelo qual tais títulos foram inseridos ao longo do texto.

Ciente das exceções e da impossibilidade de correlação direta de todos os programas veiculados com o período estudado pretende-se ressaltar o rumo da programação, no intuito de colaborar com o entendimento da história que estamos tecendo para as futuras gerações. Parte-se da leitura de que as subjeti- vidades se constituem e integram diferentes aspectos da cultura, influenciadas por múltiplas práticas coletivas presentes no contexto social, político, educacional e midiático que, junto com a história de cada ser humano, compõem as individualidades.

\section{REVENDO A PROGRAMAÇÃO: OS COMANDANTES}

'Papai Sabe Tudo'² foi um seriado exibido na televisão brasileira a partir do início da década de 60. Era bastante popular entre as crianças e seus familiares, retratando o cotidiano de um pai de família comedido, chefe da sociedade conjugal, ou ainda "o cabeça do casal" que ministrava importantes "lições de vida". Não mais o pai autoritário, onipotente, dos tempos passados, mas o chefe de família a quem cabia a última palavra; simbolizava o saber paterno, transmitido a partir de suas vivências. Ponderado, inteligente, sempre dispunha de palavra sábia ou de solução gloriosa para as situações criadas por seus filhos.

Entre os programas infantis de grande audiência na mesma década pode-se apontar o do Capitão Furacão (1965-1969), com início no dia da estréia da TV Globo, e o do Capitão Aza ${ }^{3}$ (1966-1979), destaque da TV Tupi. Além dos desenhos animados exibidos ao longo dos programas, os dois apresentadores - ídolos da garotada de outrora -, recebiam cartas, liam mensagens e, paternalmente, ofereciam conselhos aos telespectadores mirins. As figuras femininas brilhavam apenas enquanto assistentes, como a atriz Elisângela que ajudava o Capitão Furacão e a garota-propaganda Neide Aparecida.

Quanto aos super-heróis, nesta época obtinham êxito o Super-Homem, National Kid - precursor dos heróis japoneses no Brasil -, Zorro e o Sargento Garcia, Bat Masterson - retratado como um gentleman no Velho Oeste -, e o famoso seriado 'Bonanza'. Neste último, os Cartwright - Benjamin, Adam, Hoss e Little Joe - representavam, respectivamente, o pai e seus três filhos. Os quatro, em clima de faroeste, defendiam a propriedade onde moravam, procurando corrigir injustiças.

Podemos supor que estes seriados e desenhos reproduziam o consentimento sociocultural dado ao homem, na época, para o uso da força visando à resolução de conflitos. Os protagonistas não só exerciam a defesa como buscavam a justiça, o limite, muitas vezes justificando seus atos com os conselhos transmitidos no epílogo de cada episódio. Uma análise referente ao conjunto da programação citada aponta para a reprodução do papel masculino, seja no lugar de chefe de família, de defensor do espaço público e do privado, ou, ainda, como "comandante" e conselheiro de crianças em programas dirigidos à faixa 
Brito, L.M.T. "De "papai sabe tudo" a "como educar seus pais". Considerações sobre programas infantis de TV"

etária destas.

A organização familiar hierárquica, retratada em alguns programas naquela época, reiterava a supremacia dos homens sobre as mulheres. A desvantagem física e o instinto materno eram argumentos utilizados pela sociedade para distanciar a mulher do espaço público. Ao mesmo tempo, homens eram afastados das tarefas domésticas, vistos como aqueles que "não têm jeito para isso", preparados, no entanto, para zelar por uma ética da família. As desigualdades em relação aos direitos e deveres entre homens e mulheres eram aceitas e legitimadas culturalmente. A boa mãe era aquela que se sacrificava e educava os filhos na ausência do marido, empenhada em manter um ambiente acolhedor em que todos pudessem se sentir bem.

No final da década de 60, em livros dedicados à orientação dos pais, como a obra Você quer ter um filho? (LOHMANN, 1969), encontram-se conselhos dirigidos aos futuros pais e mães, ancorados na visão do instinto materno, determinante biológico que servia de justificativa para alocar as mulheres como as mais aptas ao cuidado das crianças. Assim, ao destacar as características pertinentes à mãe ideal, Lohmann recomenda que esta deve "aprender a aceitar as coisas desagradáveis da vida sem resistência emotiva, evitando o agitar-se e o queixar-se, mantendo um otimismo neutralizador." (p.94)

Pode-se constatar que a mídia, aliada às teorias científicas da época, reafirmava o lugar da esposa como aquela que cuida dos filhos e auxilia o marido, este sim alçado à categoria de pai-herói. Nos conselhos dados aos genitores, Lohmann (1969), ao retratar as características básicas que um pai ideal deve reunir, expõe:

"Em geral, num lar, o pai é o herói, mostrando-se forte, bravo e fiel. Sabe tudo e sempre tem razão. Cada criança deseja que o pai tenha tais atributos e insiste em considerá-lo assim, apesar de experiência contrária." (p. 59)

\section{AS FEITICEIRAS}

No início da década de 70, em 'Jeannie é um gênio' ${ }^{4}$, a protagonista, recorrendo a magia, tentava proteger seu amo e senhor, Major Nelson, que muitas vezes brigava com Jeannie devido ao comportamento um tanto quanto irresponsável e irreverente desta. Já em 'A Feiticeira' ${ }^{5}$, Samantha não era um gênio, mas uma feiticeira, que tudo conseguia com seus poderes sobrenaturais. Seu marido representava o papel de chefe de família, ou tentava fazê-lo, já que muitas vezes a feiticeira, esposa dedicada, fingia aceitar as imposições de James, principalmente em relação ao comportamento de Endora (mãe de Samantha) e ao de Tábata (filha do casal), ambas feiticeiras.
O seriado 'Mulher Maravilha' ${ }^{6}$, exibido no Brasil a partir de 1976, possui uma origem interessante. A protagonista foi criada por um professor de psicologia norte- americano, que se ressentia da falta de uma heroína nas histórias em quadrinhos publicadas no período da $2^{\text {a }}$ Guerra Mundial. A personagem teve alguns episódios gravados para a TV na década de 60 , que nunca foram ao ar, e somente em meados dos anos 70 o seriado foi exibido. Este abordava as aventuras vividas por Diana, uma heroína que sai da ilha secreta onde reside e vai para a América conduzindo o oficial Trevor, que, após um desastre aéreo, caiu com seu avião na ilha em que Diana morava. Disfarçando sua identidade, a Mulher Maravilha trabalha como assistente de Trevor na Força Aérea dos E.U.A., e, na segunda fase da série, para o serviço secreto norte-americano sob as ordens do filho de Trevor.

No seriado 'As Panteras', que surgiu no final dos anos 70, três belas detetives atuavam sob as ordens do misterioso Charlie, conforme o título original : "Charlie's Angels".

Não se pode desprezar o fato de que, nesta mesma década, o movimento feminista obteve repercussão na sua luta contra a opressão direcionada às mulheres, incluindo a contestação da ordem familiar hierárquica vigente e a busca da igualdade de direitos entre homens e mulheres.

Se 'Papai sabe tudo', 'Bonanza' e outros representavam o estereótipo de homem ponderado, chefe de família, em 'A Feiticeira' e 'Jeannie é um gênio' é dada notoriedade ao fato de que a mulher governa de esguelha, quando, com jeito e persuasão, impõe sua vontade e influencia o marido, que permanece com o poder de representação familiar. Retrata-se a astúcia das mulheres por meio de poderes mágicos, secretos, ou do "jeitinho feminino".

Dessa forma, ajudando a sustentar estereótipos, esses seriados e desenhos parecem desempenhar uma função estratégica. Conforme alerta Cleinman (2002):

"Criando demandas de consumo, impondo sonhos e fantasias, naturalizando exclusões e dominações, a Comunicação vai ocupando espaços e legitimando-se como fonte de verdade. Só que ela é a bocca de la veritá do capital. E é deste lugar que determina a concepção dos valores e princípios que devem reger nossas vidas, como, por exemplo, o afeto." (p.30)

\section{UNIDOS CONTRA O MAL}

No início da década de 80 cresceu o número de programas infantis que equipararam a figura feminina à masculina. 'He-Man' ${ }^{7}$ que começou a ser exibido nos Estados Unidos em 1983, e sua irmã 'She- 
Ra' ${ }^{8}$ - que em 1985 conquistou série própria - encantaram a garotada da época com seus superpoderes. O Príncipe Adam era forte, musculoso, e com sua espada mágica gritava: "pelos poderes de Greyskull: eu tenho a força!", expressão imitada pelas crianças. Muito sucesso também fez a série 'Changeman' ${ }^{9}$, produzida em 1985. Apresentava um grupo de cinco jovens que se transformavam no esquadrão relâmpago Changeman, composto por três heróis e duas heroínas: Change Mermaid e Change Phoenix. O seriado "Casal 20" (Hart to Hart), uma idéia do escritor de "Jeannie é um gênio", reunia um homem e uma mulher "nota dez" que, juntos, conseguiam êxito em suas missões.

Na programação infantil, o "Show do Bozo", exibido no SBT de 1981 até 1991, alterna a preferência da audiência com Xuxa, que teve sua estréia em 1986, na Rede Globo, e com Angélica, em sua "Nave da Fantasia", em 1987, na TV Manchete, iniciando-se a ascensão e o privilégio femininos na condução de tais programas. Percebendo os novos rumos da TV, o SBT não perdeu tempo, substituindo o show do palhaço pelo programa de Mara Maravilha (curiosamente também MM). Observa-se que, enquanto na década de 60 os protagonistas destes programas eram homens, que transmitiam conselhos aos pequenos telespectadores, a partir de meados da década de 80 ocorre uma progressiva troca de comando, quando os programas infantis passam a ser divulgados por sensuais apresentadoras, que, entre outras coisas, ensinam a garotada a escovar os dentes. Cabe recordar ainda que tais conselhos, entoados nas músicas e jogos que divertem o público, recomendam insistentemente o consumo de alimentos, produtos de higiene, e outros itens, responsáveis pelo patrocínio do programa - unificando, assim, as figuras de apresentador e vendedor. Nesse sentido Bauman (2003), em análise sobre a indústria do entretenimento, observa:

"A autoridade das celebridades deriva da autoridade do número - ela aumenta (e diminui) com o número de espectadores, ouvintes, compradores de livros e de discos." (p. 64)

Interessante contribuição oferece Dumon (1992), quando informa que, no âmbito da sociologia, nos anos 80, foram realizados estudos para se averiguar o que estava sendo denominado de "novos pais". Concluiu-se que estes eram um produto direto das mudanças iniciadas na década de 70 , que contribuiram para a visão de parceria entre os cônjuges, quando a família passou a ser classificada como "simétrica". Também em Figueira (1986) encontra-se referência a respeito das diferenças entre a unidade familiar da década de 50 , reconhecida como hierárquica, e a família da década de 80 , vista pelo autor como "igualitária". No entanto, esses modelos famili- ares não podem ser encarados como estanques, absolutos em cada época e lugar, na medida em que se observa com freqüência a coexistência do hierárquico e do igualitário, ou ainda a oscilação de um pólo a outro, dependendo da situação enfrentada.

\section{NÃO É A MAMÃE!}

Na década de 90, ocorreu o lançamento de 'Os Simpsons' ${ }^{10}$, série apreciada até hoje em diversos países. Logo depois, surgiu 'A Família Dinossauro' ("The Dinosaurs"), que estreou no Brasil em 1992, com forte merchandising em torno do título. O desenho dos Simpsons se propõe a retratar uma família norte-americana de classe média, abordando assuntos considerados polêmicos como racismo, adultério e homossexualismo, com ironia, utilizando sátiras em suas contestações sociais (Pimenta, 2000). No entanto, tem-se como ponto em comum nos dois seriados o fato de que as mães são retratadas como pessoas equilibradas, sensatas - a referência familiar - enquanto Homer Simpson e Dino da Silva Sauro demonstram incompetência para a solução dos problemas apresentados, relegados à condição de "homem objeto" ${ }^{11}$, logo reconhecidos como "sexo frágil" ${ }^{12}$.

Nos dois desenhos, o papel representado pelo homem é enfraquecido enquanto imagem social, quando, contrariamente, o das mulheres é enaltecido. Ou seja, é feita uma comparação de atitudes e comportamentos, sendo o pai menosprezado no que diz respeito à dimensão simbólica da palavra, com prováveis repercussões na fragilização de sua figura. Compreende-se que tais abalos se estendem não só à figura masculina, como também à autoridade paterna na forma como era representada na família nuclear. $\mathrm{Na}$ visão de Nolasco (2001), "Homer é uma referência importante para a série. É por seu intermédio que a inteligência de Lisa e o senso de justiça de Marge são potencializados e mais positivados." (p. 55)

Da antiga serenidade do "papai sabe tudo", caminhamos para uma supervalorização da figura feminina, ao preço, porém, de uma redução da validação social de ser pai, lembrando, talvez, a música cantada na mesma época, pelo grupo Ultraje a Rigor: "Inútil / A gente somos inútil". ('Inútil', Roger Rocha Moreira)

\section{SUPERPODEROSAS}

Hoje, se observa grande mudança nos diferentes papéis acumulados pela mulher, acarretando, conseqüentemente, um certo estremecimento no sólido lugar ocupado, até então, pelo homem. Enquanto por um lado se pode argumentar que muitas mulheres trabalham, são independentes financeiramente, responsáveis e provedoras da família, em relação aos homens, as mudanças aparecem mais como decor- 
Brito, L.M.T. "De "papai sabe tudo" a "como educar seus pais". Considerações sobre programas infantis de TV"

rentes destas transformações.

Em pesquisa realizada com pais e mães separados (BRITO, 2002), foi constatado o quanto muitas mulheres que detêm a guarda dos filhos acabam contribuindo, ainda que de forma indireta, para o afastamento do ex-marido do convívio com as crianças. Essas mães justificam que querem preservar sua individualidade, que se orgulham de poder sustentar os filhos e que não aprovam a interferência do ex-marido no modo como criam os rebentos. Apesar das queixas que fazem a respeito da sobrecarga que assumem, algumas vezes parecem optar pela posição de "todopoderosa" - utilizando termo cunhado por Hurstel (1999) -, ao conduzir a educação dos filhos.

O desenho 'As Meninas Superpoderosas' ${ }^{13}$ vem causando sensação, ultimamente, com Lindinha, Florzinha e Docinho. A série, veiculada nos EUA a partir de 1998, além de divertir a criançada, já está incluída no rol de temas de festas infantis, artigos de papelaria e souvenirs, como chaveiros e canetinhas, sendo identificada como uma "febre mundial". Super-heróis femininas combatem o crime e as forças do mal, conforme divulga o anúncio do programa, que expõe: "as meninas superpoderosas, mais fortes do que qualquer coisa." Na música-tema do desenho, as heroínas explicam: "preciso de ação, preciso de aventura, preciso dar um soco." Com seus poderes, as meninas não só salvam sua cidade, como também o professor, seu criador, ignorando, por vezes, os conselhos e as proibições deste, que não exerce uma autoridade paterna sobre as meninas. Da mesma forma, o prefeito da cidade, para manter a paz da comunidade, recorre sempre às três meninas, deixando claro sua inabilidade, ou incompetência, enquanto figura de autoridade, para dar solução às ameaças ou aos perigos que afetam a localidade.

Conforme resume o autor do desenho, o cartunista Craig McCrachen, as meninas reúnem doçura e força, ingredientes que contribuíram para o sucesso, tanto entre o público infantil, quanto entre jovens e adultos. Em entrevista publicada em um jornal (WERNECK, 2002, p.1), o cartunista justifica: "toda mulher gosta de se achar bonita e delicada e, ao mesmo tempo, poderosa. Elas usam os produtos como símbolos de suas próprias personalidades". Desenho também recente, que antecede na programação o das Superpoderosas, é o das 'Trigêmeas' ("The Triplets"), meninas sabidas que sempre vencem a bruxa Nilda e ajudam os amigos que se encontram em apuros.

Em compensação, "Johnny Bravo", rapaz forte, usa um "charmoso" topete e se acha maravilhoso, possuidor de "poderosos sensores de gatinhas". O jovem é muito ligado à mãe - uma mulher excêntrica , que acha que o filho deve ser o melhor em tudo. Johnny revela, além dos traços narcísicos, um racio- cínio simplista; freqüentemente, o anti-herói apanha das mulheres, "gatinhas" mais espertas do que ele, que o chamam de idiota ou imbecil. Seu topete parece semelhante ao que alguns jovens usam atualmente - ou seria o contrário?

Constata-se que, agora, na luta do bem contra o mal, figuras femininas são as protagonistas, heroínas que defendem "os normais" ${ }^{14}$. Enquanto, por exemplo, Super Homem defende o planeta Terra, as Meninas Superpoderosas - com capacidades superiores ao de seu criador -, exercem função semelhante na cidade de Townsville, diferenciadas, entretanto, da Mulher Maravilha, que oculta seus poderes e sua identidade trabalhando sob as ordens de um homem e de Mermaid e Phoenix , que atuam no grupo Changeman.

Vale lembrar, todavia, que a luta travada pelo feminismo, de acordo com as que o lideram na atualidade, não aponta para uma troca de lugares e, sim, para a não discriminação, fato que conduz à interpretação de que redimensionar o papel, ou desmistificar as diferenças até então sustentadas, não significa assumir o lugar do outro, tendo, para isso, que o desqualificar.

\section{COMO EDUCAR SEUS PAIS' ${ }^{15}$}

No presente, junto com os desenhos destacados no item anterior, são exibidas diversas séries que apresentam as crianças como protagonistas, conforme programação divulgada pelos canais de TV.

"Rugrats", lançado originalmente na década de 90 e traduzido no Brasil como 'Os Anjinhos', continua tendo grande aceitação. A série expõe as situações da vida a partir do ponto de vista dos bebês, sendo que os adultos, o pai, a mãe e o avô, são retratados como aqueles que apenas cuidam das necessidades básicas das crianças.

"Rocket Power" reúne quatro crianças, personagens principais, que formam a equipe Rocket e gostam de aventuras e esportes radicais como skate, bike, patins, surf etc. A única menina do grupo, Reggie, destaca-se nos esportes, além de ser a mais justa e madura, responsável pela edição da revista "Reggie's Zine". Ray, o principal adulto do desenho, pai de Reggie e Otto, é dono de uma lanchonete e também admirador de esportes como os filhos. No entanto, seu comportamento assemelha-se mais ao de um irmão dos meninos.

'Os Thornberrys' ("The Wild Thornberrys") focalizam uma família que viaja por diferentes países para a realização de documentários sobre animais. Além de revelar preocupações ecológicas, observa-se no desenho que Eliza, a filha mais nova, é quem muitas vezes salva a família de grandes dificuldades enfrentadas, já que a menina tem o poder de conversar com os animais. O pai de Eliza é um romântico apre- 
sentador dos documentários que são filmados e produzidos por sua esposa.

"South Park", lançado como desenho nos EUA em 1997, reúne quatro terríveis menores de idade cercados por adultos irresponsáveis. Um desenho cáustico, com linguagem grosseira, que supera, em muito, as críticas sociais desferidas pelos "Simpsons".

Digno de nota é que, atualmente, os desenhos são apresentados, quase sempre, por crianças ou adolescentes, que fornecem conselhos diretamente relacionados ao consumo de produtos derivados das séries ou de seus patrocinadores. Em visita ao site de comunicação de uma empresa multinacional do setor de laticínios, foi encontrada a informação de que algumas de suas marcas de biscoitos e bolos passaram a utilizar personagens de desenhos animados, como "Rugrats", "Rocket Power", "Jimmi Neutron" e "Thornberrys", a partir de uma parceria estabelecida com o canal de TV por assinatura que veicula tais desenhos. Segundo um dos diretores da empresa, "o objetivo das novidades é estabelecer uma identificação mais forte dos produtos com os desejos e o dia-adia de seu público-alvo."

"O poder do consumo jovem" é matéria de capa da Revista Isto É/Dinheiro de 16 de julho de 2003. Na reportagem, especialistas em marketing explicam a importância que vem sendo dada aos jovens pelas empresas, já que se percebe a crescente influência destes sobre o que é consumido no espaço doméstico. Segundo esclarecimentos de uma diretora de agência de publicidade consultada para a matéria, "isso acontece porque eles são os mais bombardeados pela mídia". Caracterizados na matéria como a "moçada do consumo", público-alvo no qual as empresas têm procurado investir maciçamente, o jornalista conclui a matéria conjeturando: "É, parece que o poder jovem já não tem limites". (SAMBRANA, 2003, p.57)

Não pode ser desprezado o dado de que, em nossa sociedade, a responsabilidade educativa de pais e mães está relacionada à proteção de seus filhos e à imposição de limites, um exercício contínuo de transmissão. Para isto, o papel dos responsáveis deve ser claramente definido, e aqueles que os representam em cada sociedade devem estar autorizados e legitimados socialmente. Fundados no lugar de autoridade ${ }^{16}$, devem garantir às crianças um suporte permanente na sua socialização, situação que hoje é admitida como apropriada não só ao interesse individual, mas também ao interesse público. Caso contrário, como na música cantada pelo grupo Tribalistas, escutaremos o insistente refrão: "Não sou de ninguém / Eu sou de todo mundo" ('Já sei namorar', Arnaldo Antunes, Carlinhos Brown e Marisa Monte)

No rumo desta preocupação, reportagem veiculada em jornal (INTRATOR, 2003) discute o ama- durecimento precoce de crianças levadas a consumir objetos próprios para adultos, fato interpretado como uma negação do direito à infância. Menciona-se textualmente, na reportagem, o quanto parece difícil aos pais sustentarem por muito tempo o seu lugar junto aos filhos, ou seja, o lugar de autoridade, de transmissor de valores, já que sofrem diversas pressões sociais para que tornem seus filhos, cada vez mais cedo, autônomos, ou, quem sabe, consumidores autônomos.

Entretanto, no mesmo jornal, no caderno referente aos programas de televisão, há um texto que se refere a um novo desenho veiculado em canal de TV por assinatura. "Kids next door", traduzido como 'A turma do bairro' é apresentado como a única nova produção lançada pelo canal, na América Latina, no ano de 2003. No desenho, um grupo de crianças de 10 anos de idade aproximadamente, luta contra o que qualificam como "tirania dos adultos", buscando a garantia de seus direitos, como, por exemplo, o de comer apenas o que querem e de acordar tarde. Reunindo forças contra os adultos, os agentes da turma travam verdadeiras batalhas para realizar só o que têm vontade (FERNANDES, 2003). Em outra edição da mesma publicação, datada de setembro de 2003, a página 17 é dividida entre uma entrevista com o criador de 'A Turma do Bairro' e a apresentação no Brasil de um novo seriado cômico - talvez para adultos -, estrelado por quatro homens com idades próximas aos 50 anos, denominado "Manchild", sendo sugerida a tradução "homem - criança".

\section{CONCLUSÃO}

Constata-se que as imagens e os sons transmitidos nos programas infanto-juvenis das últimas décadas vêm progressivamente retratando uma desvalorização dos responsáveis por crianças e adolescentes, não fornecendo um suporte social necessário ao sustento e à manutenção da autoridade de tais adultos. Acompanhando o movimento dialético da mídia destacado no início deste trabalho, tal fato pode ser interpretado como uma estratégia, insistentemente difundida, que contribui para uma mudança de comportamentos, quando apresenta, inicialmente, homens desqualificados na sua função de transmissão, meros espectadores do crescente poder feminino e, depois, crianças transformadas em figuras de autoridade.

Se muitas são as queixas a respeito de uma aparência adulta imposta aos menores de idade recorrendo a roupas e outros objetos de consumo, devese compreender que eles não podem ser a própria referência, como também não devem ser levados a enxergar suas figuras parentais como frágeis ou destituídas de qualquer autoridade, para as quais balançam os ombros e cantam o refrão "Tô nem aí / Tô nem aí" 
Brito, L.M.T. "De "papai sabe tudo" a "como educar seus pais". Considerações sobre programas infantis de TV"

('Tô nem aí', Luka e Latino). Neste rumo, identificados com seus heróis-mirins e instigados para desejos e ideais de tipo consumista, parecem encontrar menores objeções ou limites, dadas a insignificância e a indefinição do alcance da autoridade de seus responsáveis.

Assim, ao pensar em relações familiares democráticas, pode ser apropriado indagar se a nossa sociedade está oferecendo a ancoragem, ou os apoios simbólicos sociais, adequados e suficientes para que este objetivo seja alcançado. Acredita-se no ideal de homens e mulheres como cidadãos com igualdade de direitos e, como nos alerta Hurstel (1999), "definidos por direitos e deveres antes que por poderes" (p.141).

Pai e mãe possuem direitos e deveres em relação à educação dos filhos, mesmo que não permaneçam casados. Portanto, devem ser oferecidas condições no campo social que referendem esta noção, sob a pena de estarmos retirando das crianças e jovens, simbolicamente, as amarras que sustentam seus responsáveis como titulares da função de transmissão.

\section{NOTAS}

${ }^{1}$ Amostra composta por crianças, adolescentes, jovens adultos e adultos.

2 Título original: "Father Knows Best"

${ }^{3}$ No programa em questão, Aza era escrito com Z.

${ }^{4}$ Título original: "I dream of Jeannie".

${ }^{5}$ Título original: "Bewitched ".

${ }^{6}$ Título original: "Wonder Woman"

7 Título original: "He-Man and the Masters of the Universe"

${ }^{8}$ Título original: "She-Ra : Princess of Power"

${ }^{9}$ Título original "Dengeki Sentai Changeman"

${ }^{10}$ Título original: "The Simpsons". Foi em 1990 que o desenho passou a ser uma série fixa, nos EUA, com episódios de 30 min.

11 Título de quadro apresentado no programa Fantástico, da Rede Globo de TV, em 2003.

${ }^{12}$ Programa derivado do quadro mencionado na nota anterior, apresentado no mesmo canal de TV, de outubro a dezembro de 2003.

${ }_{13}$ Título original: "Powerpuff girls"

14 Título de programa exibido semanalmente pela Rede Globo de TV até meados de 2003.

${ }^{15}$ Título de programa baseado no livro homônimo do grupo Obrigado Esparro, apresentado pela Rede Globo de TV em abril de 2003.

${ }_{16}$ Bruel (1998) recorda que a noção de autoridade parental, tal como empregada por Hannah Arendt, não pode ser interpretada como uma relação de força ou de persuasão, mas que se encontra relacionada "ao reconhecimento de alguém como fundado a se exprimir a partir de certo lugar " (p.4).

\section{REFERÊNCIAS}

BARROS FILHO, CLóvis e MARTINO, Luís Mauro. O Habitus na comunicação. São Paulo: Paulus, 2003.

BAUMAN, Zygmunt. Comunidade : a busca por segurança no mundo atual. Rio de Janeiro: Jorge Zahar Ed., 2003.

BRITO, Leila. Impasses na condição da guarda e da visitação - o palco da discórdia. In: CONGRESSO BRASILEIRO DE DIREITO DE FAMÍLIA, 3.2001. Anais.... Belo Horizonte: IBDFAM/ Del Rey, 2002, p.433-448.

BRUEL, Alain. Assurer les bases de l'autorité parentale. Pour rendre les parents plus responsables. Paris, mai 1998, mimeo.

CLEINMAN, Betch. Comércio de luas e estrelas. Revista Jurídica - edição especial, Belo Horizonte, ano IV, n.8, p.30-31, maio 2002.

DUMON, Wilfried. Mutation des modèles familiaux em Europe Occidentale. Familles em Mutation dans une société em mutation, Bruxelles: Unesco/Conseil International des Femmes, p.25-33, 1992.

FERNANDES, Lilian. Contra a tirania dos adultos. $O$ Globo, Rio de janeiro, 13 abril 2003. Revista da TV, p.21.

FIGUEIRA, Sérvulo (Org.) Uma nova família? O moderno e o arcaico na família de classe média brasileira. Rio de Janeiro: Zahar, 1986.

INTRATOR, Simone. Direito à infância. O Globo, Rio de Janeiro, 13 abr. 2003. Jornal da Família, p.1-2.

HURSTEL, Françoise. As novas fronteiras da paternidade. Campinas: Papirus, 1999.

LOHMANN, Alberto. Você quer ter um filho? Rio de Janeiro: Temário, 1969.

MEDRADO, Benedito. Homens na arena do cuidado infantil: imagens veiculadas pela mídia. In: ARILHA, S., RIDENTI, S. e MEDRADO, B. (orgs.). Homens e masculinidades: outras palavras. São Paulo: Ecos, 1998, p.145- 162.

NOLASCO, Sócrates. De Tarzan a Homer Simpson. Rio de Janeiro: Rocco, 2001.

PIMENTA, Letícia. Irreverente e irresistível. Jornal do Brasil. Revista Super TV, ano IV, n.72, 22-28 setembro 
de 2000, p.2-3.

ROCHA-COUTINHO, Maria Lúcia. Dos contos de fadas aos superheróis: mulheres e homens brasileiros reconfiguram identidades. Psicologia Cínica, Rio de Janeiro, v. 12, n.2, p.65-82, 2001.

SAMBRANA, Carlos. Geração Teen. Isto É/Dinheiro. São Paulo, n.307, 16 julho 2003, p.54-57.

SARLO, Beatriz. Escenas de la vida posmoderna. Buenos Aires: Ariel, 1995.

WERNECK, Alexandre. Superpoderosas, mas femininas. Jornal do Brasil, Rio de Janeiro, 4 julho 2002. Caderno B, p. 1e 3.

Leila Maria Torraca de Brito é Professora Adjunta do Instituto de Psicologia da Universidade do Estado do Rio de Janeiro. O endereço eletrônico da autora é: torraca@uerj.brouleila.brito@skydome.net

Leila Maria Torraca de Brito De papai sabe tudo a como educar seus pais: considerações sobre programas de TV infantis.

Recebido: 15/10/2004

$1^{\text {a }}$ revisão: 23/12/2004

$2^{\text {a }}$ revisão: 28/03/2005

Aceite final: 4/04/2005 